\title{
Experimental study on Jet-A pool fire at high altitude
}

Zhihui Zhou ${ }^{15}$, Wei Yao ${ }^{2}$, Haihang $\mathrm{Li}^{1}$, Chao-Hsin $\mathrm{Lin}^{3}$, Joe Yin ${ }^{4}$, Ted Wü ${ }^{3}$, Oliver C. Meier ${ }^{3}$, Jian Wang ${ }^{1 *}$

1. State Key Laboratory of Fire Science, University of Technology and Science of China, Hefei 230027, PR China;

2. LHD, Institute of Mechanics, Chinese Academy of Sciences, Beijing, 100190, P. R. China;

3. Eng-ECS PD \& Tech Programs, The Boeing Company, 3003 West Casino Road Everett, WA 98204, USA;

4. Research Collaborations and Environment Program Director, Boeing (china) Co. Ltd., Beijing 100027, PR China;

5. Department of Civil and Architectural Engineering, City University of Hong Kong, Hong Kong 999077, PR China;

${ }^{*}$ Corresponding Author E-mail: wangj@ustc.edu.cn

\begin{abstract}
For the further assessment on cargo fire hazard, full-scale Jet-A pool fire tests under the specifications of FAA Minimum performance standard (MPS) were conducted in sea-level Hefei and high-altitude Lhasa. A square insulation board $(1.2 \mathrm{~m} \times 1.2 \mathrm{~m})$ was place upon the fuel pan to simulate the effect of ceiling on fire plume. The experimental results indicates that the mass burning rate is proportional to the $2 / 3$ power of the ambient pressure, in accordance with the theoretical prediction for convection-dominant fires. The analysis shows that the flame height increases slightly at high altitude. At higher altitude, the centerline temperature decreases in the flame region but increases in the intermittent region. The addition of ceiling increases the mass burning rate and the centerline temperature, although the effect on centerline temperature is observed to be weaker in Lhasa.
\end{abstract}

KEYWORDS: Jet-A; Pool fire; high altitude; mass burning rate; flame temperature

\section{NOMENCLATURE LISTING}

\begin{tabular}{|c|c|c|c|}
\hline$D$ & pan diameter $(\mathrm{m})$ & $r$ & stoichiometric ratio \\
\hline$L$ & pan side length (m) & $c_{p}$ & specific heat of air \\
\hline$P$ & pressure $(\mathrm{KPa})$ & $\rho_{\infty}$ & air density \\
\hline$T$ & temperature $(\mathrm{K})$ & & \\
\hline$H_{f}$ & flame height $(\mathrm{m})$ & \multicolumn{2}{|c|}{ subscripts } \\
\hline$Z^{\prime}$ & height from fuel level (m) & $l$ & Lhasa \\
\hline$\Delta h_{c}$ & heat of combustion $(\mathrm{kJ} / \mathrm{kg})$ & $h$ & Hefei \\
\hline$\dot{m}^{\prime \prime}$ & burning intensity $\left(\mathrm{g} / \mathrm{m}^{2} \mathrm{~s}\right)$ & $f$ & flame \\
\hline$\dot{m}$ & burning rate $(\mathrm{g} / \mathrm{s})$ & $\infty$ & ambient \\
\hline
\end{tabular}

\section{INTRODUCTION}

High altitude has shown a significant effect on fire behavior [1-8], which aroused the research interest for airplane safety. An early experimental study on fuel combustion characteristics at different altitudes were carried out by Wiser [1].Li et al [2] reported the experimental measurements of on n-heptane $(D=0.305,0.375 \mathrm{~m})$ and wood crib fires in Hefei (a sea-level city, $50 \mathrm{~m} / 100.8 \mathrm{KPa})$ and Lhasa (Tibet city, $3,650 \mathrm{~m} / 64.3 \mathrm{KPa}$ ), which aroused a general concern on high altitude fires. Since then plenty of studies of the behavior of high altitude fires were conducted [3-7]. Hu et al [3] suggested that the burning intensity (burning rate per unit area) should be a function of pool dimension $D$ and pressure $P$ as $\dot{m}^{\prime \prime} \sim f c n(D, P)$ based on the experimental measurements on $\mathrm{n}$-Heptane $(D=0.18 \mathrm{~m})$ pool fires in Lhasa and Dangxiong (another Tibet city, 4,350 m/59.1 KPa). Fang et al $[6,7]$ measured square pool fires with different sizes $(L=4 \sim 33 \mathrm{~cm})$ in Hefei and Lhasa, and pointed out that the burning intensity $\dot{m}^{\prime \prime} \sim P^{\alpha}$, where the exponent $\alpha$ was determined by the dominating flame heat feedback term. Rectangular burners with different aspect ratio were used in the pool fire tests by $\mathrm{Tu}$ et al [8], where it is found that flame temperature slightly increased at high altitude and flame height was almost insensitive to pressure. Cardboard box fires of 
different sizes as specified by FAA (Federal Aviation Administration) Minimum performance standard (MPS) [9] were tested in Hefei and Lhasa by Niu and Yao et al. [4, 5], where it is found that the mass burning rate and radiative heat flux decrease while the plume temperature increases under low pressure.

Cargo fire is a severe threat to airplane safety. A large number of fire tests [10-12] have been conducted by FAA at sea-level condition and in a space-limited pressure bomb, but few field tests at high altitude areas were conducted. As the highest plateau in this planet, Tibet known as "Roof of the World" has the unique geographic advantage in modeling the high-altitude airplane cabin environments. To assess the fire hazards of flammable liquid fires may encountered in airplane cargo fires, full-scale Jet-A pool fires $(D=60 \mathrm{~cm})$ specified by the FAA MPS were tested in Hefei and Lhasa respectively in this study. The measurements on mass burning rate and flame temperature will be presented and analyzed in the following.

\section{EXPERIMENTAL DESIGH}

The experiments were conducted in the ISO9705 full-scale Heat Release Rate Calorimeter (HRRC) platforms [13] built in Hefei and Lhasa, as shown in Fig. 1(a). The exhaust hood was surrounded by thermal insulation panels and has a $15 \mathrm{~cm}$ gap at the bottom. For the convenience of experimental observation and video recording, an $80 \mathrm{~cm}$ wide opening was left at one side of the insulation board. The schematic of fire test platform were drawn in Fig. 1(b).

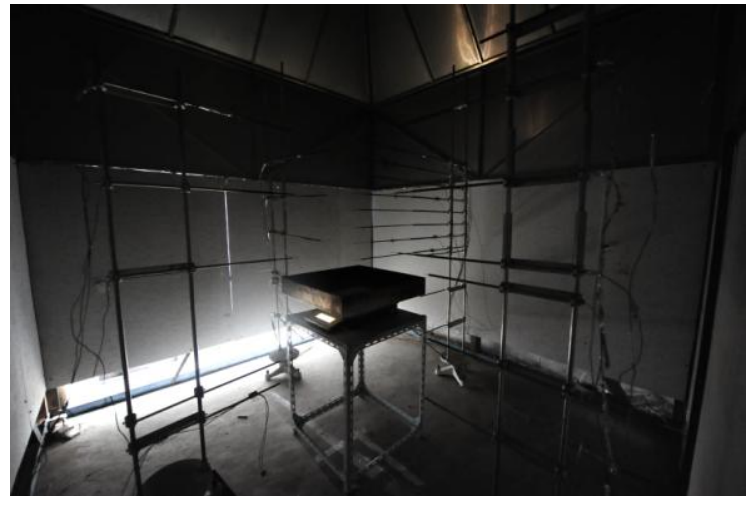

(a) Picture of HRRC platform in Lhasa

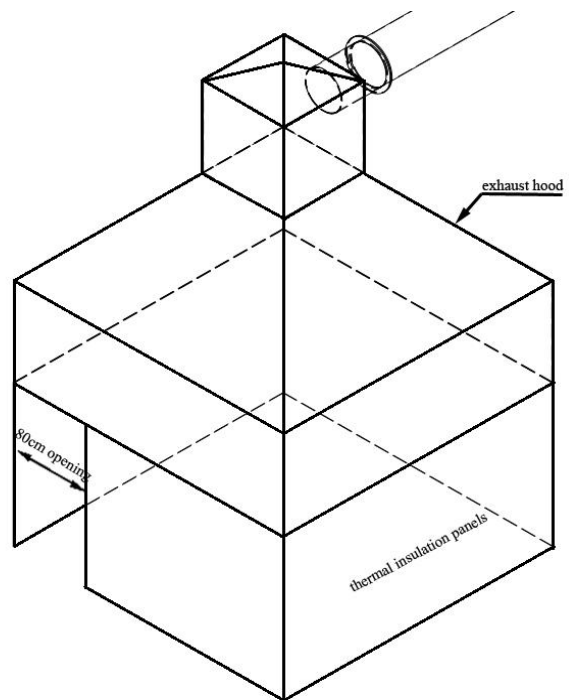

(b) Schematic of HRRC platform

Fig. 1. Fire test platform

The experimental setup was designed in accordance to Surface-Burning Fire scenario in FAA Minimum performance standard (MPS) [9], and Jet-A fuel (1.9L) fueled pool fires were tested using a square pan, which was constructed of $0.3-\mathrm{cm}$-thickness steel. The pan used in experiments was $10 \mathrm{~cm}$ in depth, and with side length of $0.6 \mathrm{~m}$. For that the Jet-A fuel is difficultly to be ignited, a small amount of gasoline (300 $\mathrm{ml}$ ) was poured on the top of Jet-A fuel as ignition source. In addition, 9.5 liters of water was placed at the bottom of the Jet-A fuel in the pan to cool the pan and minimize warping. The fuel pan was positioned at a height of $0.9 \mathrm{~m}$ on a steel table in the test room center. An electronic scale with the resolution of $0.1 \mathrm{~g}$ was placed beneath the fuel pan to record the mass loss rate. Meanwhile, to protect the electronic scale from the fire, a $1.2 \times 1.2 \mathrm{~m}$ insulation board was placed below the pan to shield the scale. The centerline temperature of flame (T1-T8) was measured by K-type armored thermocouples with diameter of $1 \mathrm{~mm}$, and response time less than 1s. These thermocouples were placed with an interval distance of $10 \mathrm{~cm}$, and the lowest one (T1) was located at $20 \mathrm{~cm}$ upon the bottom of fuel pan, as shown in Fig. 2. To simulate the ceiling of airplane cargo, a square insulation board $(1.2 \times 1.2 \mathrm{~m})$, which has been fumed to black to reduce the reradiation, was placed at a height of $0.9 \mathrm{~m}$ above the fuel pan. The tests without ceiling board were also conducted for comparison. The entire burning process was recorded by high definition camera made by the 
Sony company. Table 1 summarizes experimental configurations of the tests, and the test of each configuration was repeated at least 3 times to validate the data repeatability.

Table 1. Summary of experimental configuration.

\begin{tabular}{|c|c|c|c|}
\hline Case & Test site & Ceiling & Measurement \\
\hline $\mathrm{A}$ & Hefei & No & \multirow{4}{*}{$\begin{array}{l}\text { 1. Mass loss } \\
\text { 2. Temperature } \\
\text { 3. Video record }\end{array}$} \\
\hline $\mathrm{B}$ & Lhasa & No & \\
\hline $\mathrm{C}$ & Hefei & Yes & \\
\hline $\mathrm{D}$ & Lhasa & Yes & \\
\hline
\end{tabular}

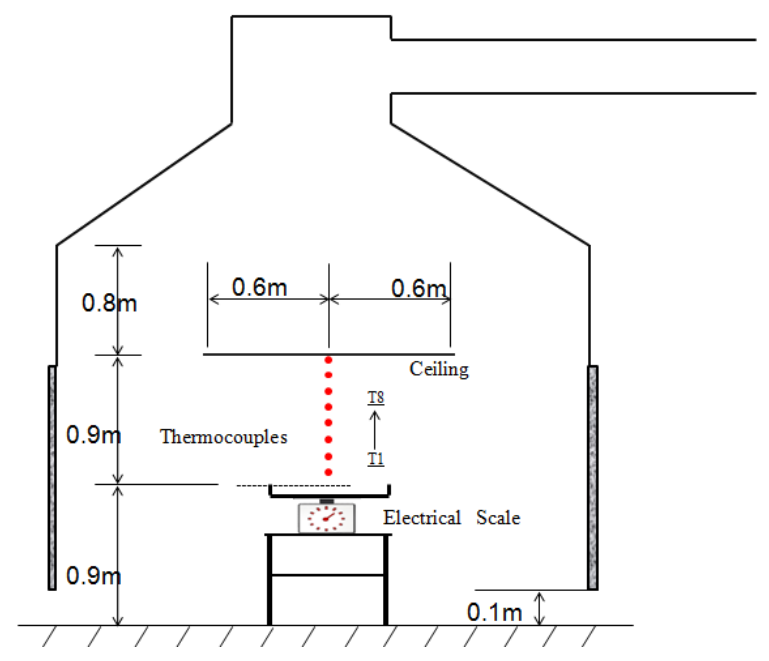

Fig. 2. Experimental setup for Jet-A pool fire research

\section{RESULTS AND DISCUSSION}

Due to the high heat of combustion of Jet-A fuel, the burning on the pool is violent, with a meters-high flame scale and drastic air entrainment compared to previously conducted solid cardboard box fires $[4,5]$. The low pressure and ceiling board significantly affect the buoyancy-driven surrounding flow and then the burning behavior. Some major parameters related to combustion characteristics are measured in Lhasa and compared with those in Hefei to characterize the fire behavior of Jet-A pool fire.

\subsection{Burning rate}

The entire burning process contains four different stages [14], i.e. initial burning stage, quasi-steady burning stage, boiling burning stage and decay stage. However, due to the cooling effect of the water at the bottom of fuel pan, the boiling burning stage can hardly be achieved, as shown in Fig. 3.

Figure 3 plots the measured burning rate curves in the whole test process, with the quasi-steady burning process marked. The figure clearly indicates that the duration of stable burning in Hefei is slightly longer than that in Lhasa, no matter for cases with or without the ceiling. Meanwhile, the decreasing pressure influences the flame heat feedback, and correspondingly leads to the decreased burning rate [6] and increasing burning time [4]. The mean burning rates of the entire combustion process of case A to D are $5.94 \mathrm{~g} / \mathrm{s}, 4.19 \mathrm{~g} / \mathrm{s}, 6.69 \mathrm{~g} / \mathrm{s}$ and $5.08 \mathrm{~g} / \mathrm{s}$ respectively. The results show that: 1) affected by the forced ventilation, the mass burning rates at low and high altitudes have the ratio of $\dot{m}_{l} / \dot{m}_{h} \approx 0.74$, for all cases, i.e. $\dot{m} \sim P^{2 / 3}$, in consistent with the theoretical correlation of pressure modeling $[15,16]$ based on convectiondominant assumption and the results of cardboard box fires [4,5], but different with the previous studies of pool fire in Lhasa $[2,6,8]$ which suggested that $\dot{m} \sim P^{\alpha}(\alpha \geq 1)$ in radiation domination; 2$)$ the addition of ceiling (square insulation board) enhances the air entrainment for burning, and the re-radiation from the 
fumed ceiling also tends to increase the flame heat feedback, although this role has been minimized by fumed to black before the tests. Finally, the ceiling effect strengthens the mass burning rate by about $40 \%$.

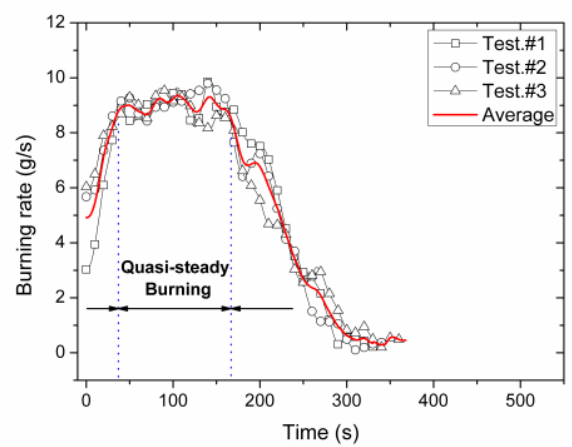

(A) Hefei-with no ceiling

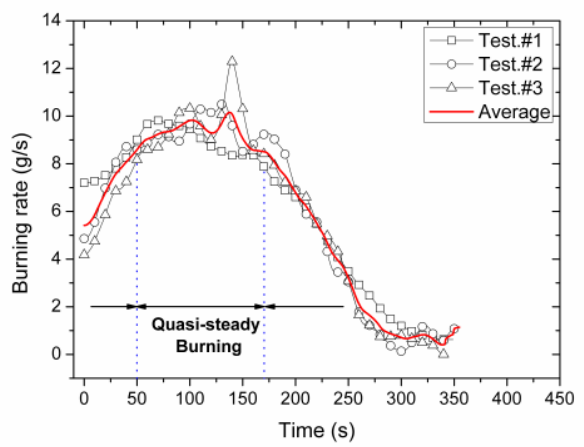

(C) Hefei-with ceiling

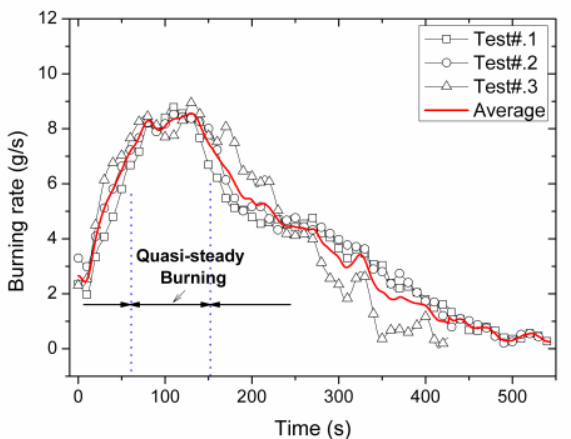

(B) Lhasa-with no ceiling

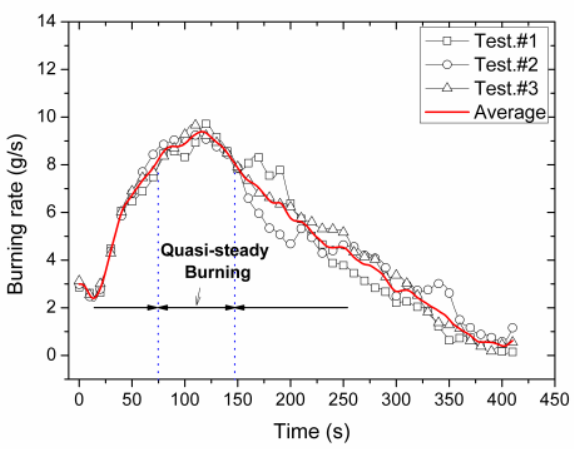

(D) Lhasa-with ceiling

Fig. 3. Burning rates of Jet-A pool fires

\subsection{Flame height and centerline temperature distribution}

Pool fire plume is principally buoyancy driven, which means flow has been induced into the plume due to an increase in temperature or consequent reduction in density [17]. The air entrainment rate is closely related to the fire plume temperature and the flame height $[18,19]$, which are critical parameters to characterize the burning behavior. An explicit equation for flame height $\left(H_{f}\right)$ is developed by Heskestad based on the virtual origin correction [20],

$$
\frac{H_{f}}{D}=15.6\left(\frac{r c_{p} T_{\infty}}{\Delta h_{c}}\right)^{3 / 5}\left(Q^{*}\right)^{2 / 5}-1.02
$$

where,

$$
Q^{*}=\frac{\dot{m} \Delta h_{c}}{\rho_{\infty} c_{p} T_{\infty} \sqrt{g} D^{5 / 2}}=\frac{\dot{m} \Delta h_{c}}{11.5 \cdot P D^{5 / 2}}
$$

Here $\mathrm{r}$ is the stoichiometric air to fuel ratio, $\Delta h_{c} / r \approx 3000 \mathrm{~kJ} / \mathrm{kg}$ [21], and $\mathrm{P}$ is the ambient pressure in $\mathrm{KPa}$. From Eq. (1) and (2), $H_{f}=1.46\left(\dot{m} \Delta h_{c} / P\right)^{2 / 5}-1.02 D$, and the mean flame heights predicted for case A to D are $1.51 \mathrm{~m}, 1.59 \mathrm{~m}, 1.61 \mathrm{~m}$, and $1.77 \mathrm{~m}$ respectively, with the assumption of a constant heat of combustion $\left(\Delta h_{c}=43.5 \mathrm{~kJ} / \mathrm{g}\right)$. The expression indicates that the flame length increases under lower pressure, which has been experimentally observed by $\mathrm{Li}$ et al $[2,3]$ and $\mathrm{Niu}$ et al $[4,5]$. Meanwhile, because the ceiling is 
sufficiently low $\left(H_{f}>0.9\right)$ for direct flame impingement, part of the flame was deflected horizontally and becomes the ceiling jet flame [21], as shown in Fig. 4.

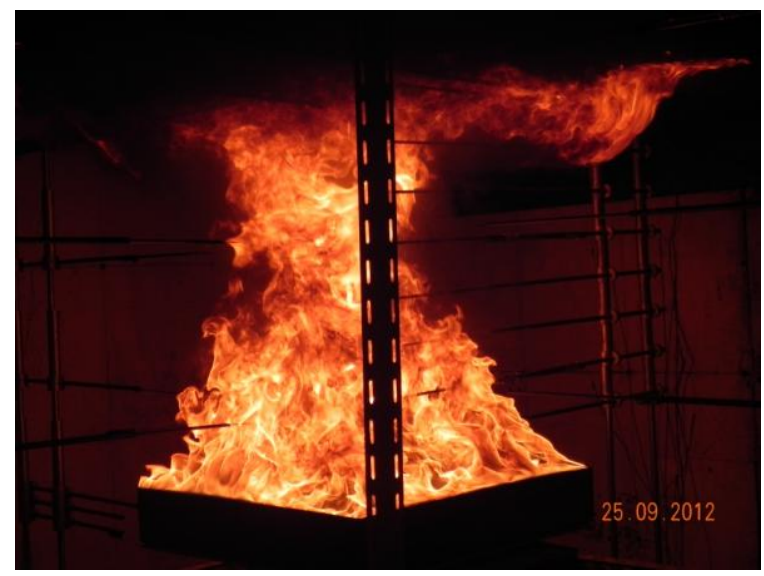

Fig. 4. Figure of flame impinging to the ceiling

McCaffrey [22] investigated the average temperatures on the centerline of axisymmetric buoyant methane diffusion flames on a $0.3 \mathrm{~m}$ square porous burner, and divided the while flame into three regions, i.e. flame, intermittent and plume, which can be scaled by the relation of $Z /\left(Q^{*}\right)^{2 / 5}$.

Figure 5 (a) plots the centerline temperatures rise $\left(\Delta T=T_{f}-T_{\infty}\right)$ for cases without ceiling in Hefei and Lhasa. Using Eq. (2), the temperature data were correlated against $Z /(\dot{m} / P)^{2 / 5}$. The fitting results for intermittent region indicate that the exponent $\eta$ is 1 at sea-level altitude, which is in accordance with the previous study [22], but $\eta$ decreases to a lower value at high altitude. The deceasing pressure produces a higher temperature in the intermittent region, which is because the local equivalence ratio, i.e. the fuel fraction relative to the reduced oxidizer concentration rises towards the unity [23]. The temperature in flame region ( $\Delta T>400 \mathrm{~K}$ ) measured in Hefei is higher than in Lhasa, as shown in Fig. 5(a) and (b), which is because of the decreasing of local equivalence ratio [23]. Besides, the centerline temperatures in cases with ceiling are much higher than those without ceiling in Hefei tests, and the ceiling produces a slower decline of the temperature along the vertical height. The added ceiling also causes the ceiling temperature (T8) slightly higher than that of the lower position (T7). However, the ceiling effect is generally weak for cases in Lhasa. For the more comprehensive studies, fire suppression tests on the ceiling fires and the measurement on temperatures at different horizontal locations under the ceiling are necessary, which will be conducted in the future.

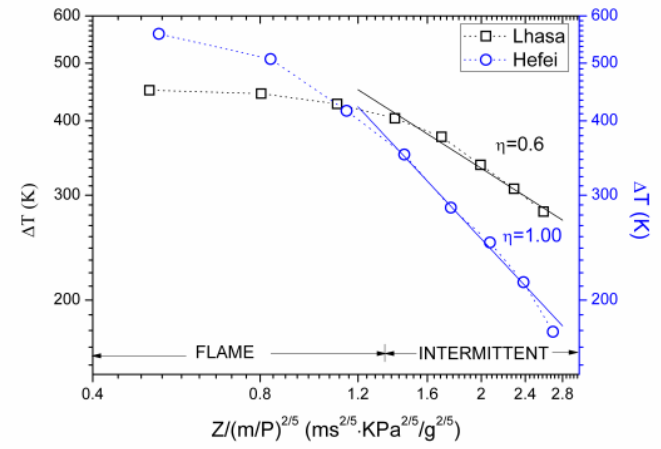

(a) Case A and B

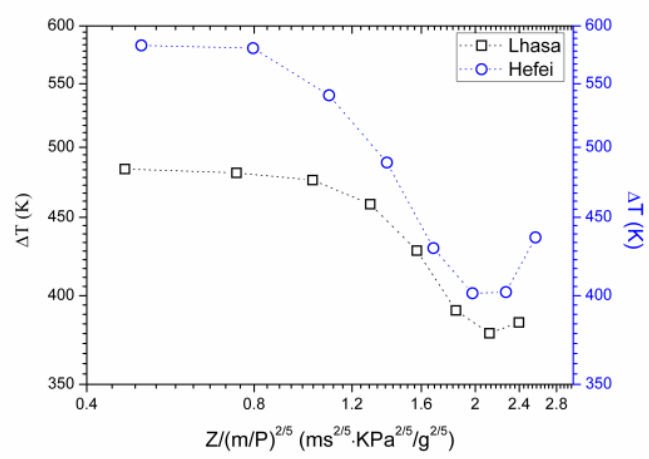

(b) Case C and D

Fig. 5. Average temperatures on the centerline of Jet-A flames 


\section{CONCLUSION}

In this study, Jet-A pool fire tests were conducted at two altitudes to examine the effect of pressure and ceiling on the fire behavior. The major conclusions are summarized as follows:

(1) The time duration of quasi-burning stage was shortened with the decreasing of pressure, and the burning rate meets the correlation $\dot{m} \sim P^{2 / 3}$, which is in accordance with the theoretical derivation of pressure modeling based on the assumption of convective domination. The addition of ceiling increases the heat feedback and correspondingly the average burning rate.

(2) The flame height is predicted to be higher at high altitude by the theoretical derivation $H_{f} \sim(\dot{m} / P)^{2 / 5}$. The centerline temperature decreases in the flame region but increases in the intermittent region at higher altitude. The temperature rise $\Delta T$ is correlated against $\left(Z /\left(Q^{*}\right)^{2 / 5}\right)^{\eta}$, where the power $\eta$ was lower at higher altitude. Similarly, the addition of ceiling strengthens the re-radiation and produces a higher centerline temperature. The ceiling effect is observed to be more obvious at sea-level altitude than at high altitude.

\section{ACKNOWLEDGEMENT}

This research was supported by the Boeing (China) Co., Ltd. The authors deeply appreciate the support.

\section{REFERENCES}

[1] Wieser, D., Jauch, P., and Willi, U., (1997) The Influence of High Altitude on Fire Detector Test Fires, Fire Safety Journal 29(2): 195-204, http://dx.doi.org/10.1016/S0379-7112(96)00042-2

[2] Li, Z., He, Y., Zhang, H., et al. (2009) Combustion characteristics of n-heptane and wood crib fires at different altitudes, Proceedings of the Combustion Institute 32(2): 2481-2488, http://dx.doi.org/10.1016/j.proci.2008.06.033

[3] Hu, X., He, Y., Li, Z., et al. (2011) Combustion characteristics of n-heptane at high altitudes, Proceedings of the Combustion Institute 26072615,http://dx.doi.org/10.1016/j.proci.2010.07.025

[4] Niu, Y., He Y., Hu, X., et al. (2012) Experimental study of burning rates of cardboard box fires near sea level and at high altitude, Proceedings of the Combustion Institute 34(2): 25652573,http://dx.doi.org/10.1016/j.proci.2012.07.041

[5] Yao, W., Hu, X., Rong, J., et al. (2013) Experimental study of large-scale fire behavior under low pressure at high altitude, Journal of Fire Sciences 31(4), http://dx.doi.org/10.1177/0734904113481326

[6] Fang, J., Tu, R., Guan, J., et al. (2011) Influence of low air pressure on combustion characteristics and flame pulsation frequency of pool fires, Fuel 90(8): 27602766,http://dx.doi.org/10.1016/j.fuel.2011.03.035

[7] Fang, J., Yu, C., Tu, R., et al. (2008) The influence of low atmospheric pressure on carbon monoxide of n-heptane pool fires, Journal of Hazardous Materials 154(1): 476483,http://dx.doi.org/10.1016/j.jhazmat.2007.10.058

[8] Tu, R., Fang, J., Zhang, Y., et al. (2012) Effects of low air pressure on radiation-controlled rectangular ethanol and n-heptane pool fires, Proceedings of the Combustion Institute 32(2): 25912598, http://dx.doi.org/10.1016/j.proci.2012.06.036

[9] Reinhardt, J.W., "Minimum Performance Standard for Aircraft Cargo Compartment Halon Replacement Fire Suppression Systems (2nd Update)," Federal Aviation Administration Report (No. DOT/FAA/TC-TN12/11), Washington, DC, 2012

[10] Blake, D., Domino, and S., Gill, W., et al., "Initial development of improved aircraft cargo compartment fire detection certification criteria," The 12th International Conference on Automatic Fire Detection (AUBE '01), National Institute of Standards and Technology, 2001, pp. 615-629 
[11] Hill, R., “2009 FAA fire safety highlights,” Federal Aviation Administration Report, Washington, DC, 2009

[12] Reinhardt, J.W., Blake D., and Marker T., "Development of a minimum performance standard for aircraft cargo compartment gaseous fire suppression systems," Federal Aviation Administration Report (No. DOT/FAA/AR-00/28), Washington, DC, 2000

[13] International Organization for Standardization, International Standard for Fire Tests-Full-Scale Room Test for Surface Products, Geneva, Switzerland, 1993.

[14] Kang, Q., Lu, S., and Chen, B., (2010) Experimental study on burning rate of small scale heptane pool fires, Chinese Science Bulletin 55(10): 973-979, http://dx.doi.org/10.1007/s11434-009-0741$\mathrm{y}$

[15] De Ris, J., Kanury A.M., and Yuen M.C., (1973) Pressure modling of fires, Proceedings of the Combustion Institute 14(1): 1033-1044, http://dx.doi.org/10.1016/S0082-0784(73)80093-1

[16] Kanury, A.M., (1975) Modeling of pool fires with a variety of polymers, Proceedings of the Combustion Institute 15(1): 193-202, http://dx.doi.org/10.1016/S0082-0784(75)80297-9

[17] Quintela, J.G. Fundamentals in Fire Phenomena, John Wiley and Sons, 2006.

[18] Ji, J., Zhong, W., Li, K.Y., Shen, X.B., Zhang, Y., Huo, R., (2011) A simplified calculation method on maximum smoke temperature under the ceiling in subway station fires, Tunnelling and Underground Space Technology 26(3): 490-496, http://dx.doi.org/ 10.1016/j.tust.2011.02.001

[19] Ji, J., Fan, C.G., Zhong, W., Shen, X.B., Sun, J.H., (2012) Experimental investigation on influence of different transverse fire locations on maximum smoke temperature under the tunnel ceiling, International Journal of Heat and Mass Transfer 55: 4817-4826, http://dx.doi.org/ 10.1016/j.ijheatmasstransfer.2012.04.052

[20] Heskestad, G., (1983) Virtual origins of fire plumes, Fire Safety Journal 5(2): 109114,_http://dx.doi.org/10.1016/0379-7112(83)90003-6

[21] Drysdale, D., An Introduction To Fire Dynamics, John Wiley and Sons, 1998.

[22] McCaffrey, B.J., "Purely buoyant diffusion flames: some experimental results," National Bureau of Standards NBSIR 79-1910, 1979.

[23] Yin, J.S., Yao, W., Liu, Q., et al. (2013) Experimental study of n-Heptane pool fire behavior in an altitude chamber, International Journal of Heat and Mass Transfer 62: 543552,http://dx.doi.org/10.1016/j.ijheatmasstransfer.2013.02.072 